Genealogy of architectural heritage: From historical document to reusable resource

PALABRAS CLAVE • PATRIMONIO • REHABILITACIÓN REUTILIZACIÓN · CONSERVACIÓN · INTERVENCIÓN

KEYWORDS - HERITACE · REHABILITATION · REUSE CONSERVATION · INTERVENTION

\section{RESUMEN}

Desde la Rehabilitación -entendida como la reutilización de un edificio para un fin diferente al que fue erigido-, vemos cómo el cambio de uso ha sido una constante en la Historia de la Arquitectura, transformando la edificación original en otra construcción híbrida, enriqueciéndola en muchos casos y desvirtuándola en otros.

La actitud frente a estas actuaciones evolucionó paralela a la valoración del Patrimonio, apareciendo diversas corrientes que buscaban garantizar la permanencia del monumento en el tiempo a pesar del cambio de uso. En relación a ello se celebraron numerosos congresos en los que se debatieron sobre pautas fundamentales de actuación. Y entre ambos polos de pensamiento se establecieron unos nexos que conformaron un marco legislativo que incidiría en el desarrollo teórico y práctico de la intervención monumental.

\section{ABSTRACT}

From the point of view of rehabilitation -understood as the reuse of a building for a different function to the one for which it was built-, the change of use of buildings has been a constant in the History of Architecture, transforming the original building into a hybrid one, enriching it in many cases, but distorting it in many others.

The attitude towards these interventions evolved parallel to the appreciation of the heritage. Several trends of rehabilitation emerged, which sought to ensure the permanence of the monument in time, despite the change of use. In relation to this, time, despite the cha purpose to debate on some fundamental guidelines referred to heritage interventions. Some ties between both ways of thought were established, which formed a legislative framework that would influence theoretical and practical dealing with monument intervention.

\title{
Genealogía del patrimonio arquitectónico: de documento histórico a recurso reutilizable ${ }^{*}$
}

\author{
ALBERTA LORENZO ASPRES** · Proyecto ARGA, Arquitecturas Rehabilitadas de Galicia, España · alberta.aspres@gmail.com
}

Fecha de recepción: 20 de agosto 2017 - Fecha de aceptación: 16 de octubre 2017

\section{INTRODUCCIÓN}

Al abordar una investigación sobre la reutilización del patrimonio arquitectónico, se convoca la necesidad de comprender la perspectiva de la rehabilitación -entendida como el cambio de uso de un edificiohaciendo énfasis en la evolución del concepto de patrimonio, desde su papel de documento histórico hasta su comprensión como un recurso reutilizable.

La reutilización de estas arquitecturas ha sido una constante a lo largo de la Historia, donde hemos observado la aparición de nuevas soluciones de revitalización en monumentos condenados a la ruina y al abandono: el cambio de uso ha supuesto su reincorporación activa en la sociedad.

Pero ha sido tras la II Guerra Mundial que se ha producido un intenso debate en toda Europa sobre la necesidad de reutilizar los edificios históricos para garantizar su supervivencia, aunque muchas veces dichas intervenciones comportaran graves pérdidas en los inmuebles. Prevalecía la doctrina de la reutilización del pasado histórico dando entrada al discurso funcional para garantizar el uso de los edificios del pasado; y como hecho general se admitía que cualquier edificio del pasado era un contenedor potencial de funciones modernas. Por todo el territorio europeo monasterios, hospitales, palacios y toda clase de edificios civiles se convertían en nuevos centros universitarios, complejos administrativos, museos, etc. tras ser vaciados-conservando únicamente sus fachadas- provocando una ausencia de relación entre la forma y la función.

El debate se perfiló en los años ochenta y noventa tras las muchas edificaciones de gran valor histórico que sufrieron la pérdida de sus características tipológicas, constructivas y/o simbólicas. Cierto es que en aquellos tiempos estas operaciones revistieron verdaderos

Este artículo deviene de la tesis doctoral Intervencións no patrimonio galego para a industria hostaleira, que analiza el sacrificio de la herencia arquitectónica tras el cambio de uso. Dicha tesis fue realizada por la autora y presentada en la Universidad de A Coruña en octubre de 2014, donde obtuvo la máxima calificación. Fue también distinguida por la Excma. Diputación de Pontevedra con el Premio a la Investigación 2014.

** Arquitecta por la E.T.S. de Arquitectura de A Coruña, Máster en Rehabilitación Arquitectónica, Máster en Gestión de Proyectos y Espacios Culturales, y Doctora en Arquitectura por la Universidad de A Coruña con la tesis Intervenciones en el patrimonio gallego para la industria hotelera, que obtuvo la máxima calificación y fue destacada por la Diputación de Pontevedra con el "Premio a la Investigación 2014". Becada en dos ocasiones por la Diputación de A Coruña, su actividad investigadora y profesional se orienta al estudio y recuperación de las arquitecturas históricas, cuyos resultados han servido como aportación a seminarios, congresos y eventos de difusión científica nacionales e internacionales, además de ser publicados en libros, revistas y actas. Actualmente dirige Proxecto ARGA, una plataforma cultural que inventaría y pone en valor todas las "Arquitecturas Rehabilitadas de Galicia". Este trabajo ha sido premiado en la XIII BEAU en la categoría de "Divulgación y Transferencia Social". 
laboratorios de ensayo y experimentación en los que se salvaron multitud de edificios. $Y$ también es cierto que entonces intelectuales, arquitectos e historiadores defendieron este tipo de actuaciones precisamente para alcanzar los fines señalados. Pero en la actualidad se tiene ya clara constancia de que se realizaron provocando fuertes alteraciones que, en definitiva, no preservaron las señales de autenticidad de los edificios: hoy no hay duda de que desaparecieron características ya irrecuperables después de las obras ejecutadas.

Sin embargo, para entender este proceso de cambio es necesario entender la evolución del concepto de Patrimonio desde su papel de documento histórico hasta su transformación en un recurso reutilizable.

Dicha evolución ha corrido paralela a la aparición de diversas corrientes que buscaban garantizar la permanencia del Monumento en el tiempo a pesar del cambio de uso, celebrándose numerosos encuentros internacionales en los que debatir sobre unas normas generales de actuación. Y entre ambas actitudes de pensamiento se establecieron unos nexos de relación que constituyeron un escenario legislativo que incidiría en el desarrollo teórico y práctico de la reutilización monumental.

\section{MARCO DE CORRIENTES DE PENSAMIENTO}

El debate sobre las preexistencias de la Antigüedad durante el siglo XIX -iniciado en Italia en la centuria anterior-, no solo no se interrumpió, sino que se extendió a otros países alcanzando un nivel de especialización cada vez mayor. El objetivo era resolver la problemática expuesta: la relación entre los distintos elementos heredados, su contextualización y la determinación de la autenticidad de los vestigios.

En la sistematización de estos prolegómenos radicaba precisamente el interés de la obra de Viollet le Duc, quien hacia 1878 incorporaba a dicho debate un nuevo lenguaje -restauración estilística- cuyo objetivo era lograr la adecuación de uso y funcionalidad de los edificios restaurados. Sus inquietudes se centraron en la adaptación de los espacios a una función designada por las nuevas necesidades, siempre bajo la comprensión racionalista de la arquitectura y mediante el empleo adecuado de nuevos materiales: "el mejor medio para conservar un edificio es hallarle una función, y satisfacer tan bien sus necesidades de uso que no haya necesidad de hacer nuevos cambios" (Rivera, 1997, pp. 49 81).

Respecto a esta actitud, Adolphe Didron introdujo además un interesante argumento en favor del carácter vivo -en cuanto a su utilidad práctica y significativa para la sociedad contemporánea- de los monumentos: "Nuestros monumentos no están muertos como los de los egipcios o los de los griegos, sino que viven y sirven a una población que se renueva todos los días" (González-Varas, 1996, pp. 31 -52).

Por otro lado, John Ruskin enunciaba una posición ante el monumento que, frente a la intervención activa de la restauración estilística, propugnaba una postura contemplativa limitada al mantenimiento y a la estricta conservación -restauro romántico. Según este punto de vista, la intervención del hombre es una intromisión en las leyes naturales y en la evolución del monumento, por lo que negaba cualquier intento de reutilización.

Con la misma actitud ante la antigüedad que Ruskin, Aloïs Riegl justificaba la restauración en aquellos monumentos con valor de contemporaneidad-donde se incluía el valor de instrumentalidad-para una necesaria reutilización del edificio y para el bienestar físico de los individuos (Riegl, 2008, pp. 53-72).

Esta idea sobre el ineludible reúso de los monumentos fue determinante para las posturas contemporáneas sobre la intervención arquitectónica, en la que se tendió a recuperar la funcionalidad en todos los casos en los que fuese posible.
La transposición de sus principios en criterios concretos para la restauración de los monumentos fue realizada por sus seguidores más directos, destacando Max Dvorák por ir más allá en la consideración del valor del patrimonio histórico antiguo. Extendió la noción a todo tipo de construcciones, independientemente de su época y estilo, así como sus implicaciones sociales y económicas. Defendía la conservación al máximo de los monumentos en su función y ambientación originales, y en su forma y aspectos inalterados (González-Varas, 1996, pp. 38-43).

El debate se trasladó entonces a Roma, donde el interés por reconstruir un centro histórico en ruinas generó una actitud hacia la recuperación de los edificios que se contraponía rotundamente a la escuela derivada de las teorías de la restauración estilística. Esta nueva acción -restauro arqueológico- aspiraba a la consolidación de edificios históricos mediante la reintegración de los elementos originales dispersos.

Adscritos a esta corriente estaban Rafaelle Stern y Giuseppe Valadier a raíz de los proyectos de restauración del Arco de Tito y del Coliseo Romano, entre otros. La continuación de sus propuestas teóricas originaría el restauro moderno, concepto consagrado por Camilo Boito, considerado como el primer gran teorizador de la restauración en Italia.

Boito admitía -por primera vez- que el monumento era una obra dual: arquitectónica e histórica a la vez y, por esta dualidad, se debía tener en cuenta no solo la necesidad de conservar y transmitir el valor histórico del bien sino también unos valores puramente arquitectónicos, definidos tanto por su forma como por sus significados y significantes. Comparaba al monumento con una obra viva y cambiante que-como su propia naturaleza de objeto arquitectónico establecía- era empleada de diferentes modos y modificada tanto en su concepción espacial como en su configuración formal originaria con aportes constructivos hechos para satisfacer las necesidades de los 
distintos usos y usuarios. Al mismo tiempo, como documento histórico que era, su fábrica no debía ser vulnerada, ya que se trataba de un eslabón que formaba parte de una larga cadena evolutiva que tenía que ser conservada íntegramente para su correcta asimilación (Fontenla, 1997, pp. 91-105).

Gustavo Giovannoni llevó hasta sus últimas consecuencias los principios defendidos por Boito. Por una parte, desarrolló un activo papel en el debate que establecía una estrecha relación entre Arquitectura y Urbanismo: punto neurálgico de toda su teoría -restauro científico-. Y por la otra, asumió una clasificación que dividía a los edificios históricos en función de su uso en monumentos vivos y muertos ${ }^{[1]}$ :

En los primeros había desaparecido su uso original y eran fundamentalmente de carácter arqueológico. Así (...) era mejor llevar a cabo una sistemática conservación para evitar el deterioro que conduciría irreversiblemente a la ruina, estableciendo un diálogo con (...) el recuerdo.

(...) Para el uso de los monumentos vivos era necesario, en ocasiones, realizar ciertas modificaciones; pero el arquitecto siempre tenía que tratar que la nueva función adjudicada al edificio restaurado no fuese demasiado diferente a la inicial para que la adaptación pudiera realizarse con un criterio de intervención poco agresivo para el documento (Fontenla, 1997, pp. 106-107).

Tras el desastre de la II Guerra Mundial, ambas actitudes -restauro moderno y restauro científicose convirtieron en procedimientos totalmente inadecuados para resolver la situación que se presentaba. Como reacción surgió una nueva teoría-restauro crítico- inspirada en la obra de Benedetto Croce.
Mientras, en España, el debate teórico se centraba sobre todo en las distintas reflexiones en torno al monumento. Por una parte, Lampérez y Romea, convertido en el líder indiscutible de la escuela restauradora, consideraba muertos a los monumentos que ya no cumplían los objetivos de uso para los que habían sido creados: se propondría solo su conservación para evitar una ruina que no resolvía el objetivo de la arquitectura. La importancia de este tipo de inmuebles residía en su valor histórico y técnico-constructivo, aportando datos de gran interés para un mejor conocimiento de una etapa de la historia de la humanidad. Por el contrario, denominaba vivos a los monumentos que mantenían su uso. En este caso, y si no fuese suficiente la simple conservación para su recuperación funcional, no solo consideraba conveniente sino también necesaria su restauración. Esta debía ser propuesta restituyendo el estilo primitivo del bien para mantener su unidad formal -base y fundamento de su belleza arquitectónica-, y siguiendo con la mayor fidelidad posible todos sus aspectos de estructura y labra originarias. Sin embargo, defendía que siempre se destacarían los elementos ex novo por medio de la analogía, admitiendo su disimulo mediante pátinas artificiales (Rivera, 1997, pp. 46-58).

En contraposición, la crítica conservadora o anti-restauradora provocó una importante inflexión en el debate teórico español de principios del siglo XX. Fue un proceso de asimilación y definición de una nueva cultura de la restauración que tendría en Torres Balbás uno de sus máximos defensores:

La mayoría de los monumentos que se restauran, es decir, que se rehacen, no se les reintegra a su anterior destino y se los deja desnudos, solitarios (...). Convirtiéndose así en obras muertas, perdiendo su contacto con la vida cotidiana y desintegrándose del ambiente en el que se hallan (...). Un edificio fue hecho para ser habitado por el hombre o por la divinidad (Ordieres, 1995, pp. 51-54).

A partir de la proclamación de la II República se llevó a cabo una importante modernización del Estado y de la sociedad con repercusiones significativas en el campo del Patrimonio Arquitectónico. Frente al sentimiento de propiedad privada como algo incuestionable se empezó a reclamar el derecho de la colectividad a la conservación y al goce del Patrimonio. Por ello el nuevo gobierno trató de recuperar el mayor número posible de edificios - muchos de ellos en pésimo estado-.

Procuremos que cada edificio dentro de lo posible, siga adscrito al mismo destino para el cual se construyó (...). Y cuando tal cosa no sea posible, démosle un destino (...) en el que sus puertas y ventanas estén siempre abiertas (...) a toda la intensidad de nuestra vida actual (Muñoz, 1989, pp. 88-103).

Y mientras la mayoría de los arquitectos españoles mantenían los criterios de actuación decimonónicos, los más vanguardistas se unieron a la tendencia europea asumiendo las propuestas italianas del restauro moderno y del restauro científico, las cuales fueron recogidas en la Ley del Patrimonio Histórico Español de 1933.

Pero con la Guerra Civil volvieron a retomarse los criterios de la escuela restauradora. Y en el resto del continente, tras la II Guerra Mundial, predominó la doctrina de la reutilización del pasado histórico dándose entrada al discurso funcional para garantizar el uso de los edificios preexistentes.

En 1963 se publicó Teoría del restauro, un ensayo de Cesare Brandi enmarcado dentro de las líneas teóricas del restauro crítico. Supuso un hito en la historia de la restauración, ya que además de abordar la conservación y la restauración de las obras de arte en particular y del patrimonio cultural en general, constituyó la
La primera vez que se distingue los monumentos por su uso es en un documento de la Comisión General de Viena para la Restauración de Monumentos en 1898. Se diferencian los monumentos vivos de los monumentos muertos; idea vigente, aunque considerada ilegítima hasta 1938 (Miarelli-Mariani 1990: 7-21). 
base teórica de la Carta italiana del restauro de 1972.

Pero a finales del pasado siglo, en el debate sobre la restauración se advertía una gran confusión en la que se superponían teorías, tendencias y normativas. Y pese a que eran expuestas distintas posturas -a veces contradictorias- con respecto a la conservación del patrimonio, se permitió retomar un diálogo anteriormente interrumpido y la restauración integral consiguió desplazar a posiciones teóricas anteriores.

Esta nueva doctrina, cristalizada en torno a los años ochenta y que tenía como principal representante a Dezzi Bardeschi, pretendía como objetivo primordial la conservación de la autenticidad de la obra de arte que, integrada por todos los aportes estratificados en su fábrica, constituía un documento irrepetible. Surgía como reacción contra una serie de excesos cometidos en reutilizaciones de monumentos que fueron convertidos en meros contenedores desprovistos de significados. Se proponía preservar tanto el valor estético como el histórico del bien y, al mismo tiempo, evitar propuestas de uso incompatibles con sus funciones originales (González-Varas, 2000, pp. 279-282).

En España-coincidiendo con la profunda reorganización institucional, política y económica que experimentaba el país- se produjo un incremento cuantitativo y cualitativo de las intervenciones en el patrimonio histórico, proceso que discurría paralelo a una renovación de los principios de la disciplina, con la incorporación del debate nacional a las corrientes internacionales y la consiguiente actualización de los contenidos discursivos.

Fue especialmente importante la asimilación de los postulados del restauro crítico, como una componente doctrinal que permeaba los interesantes aportes de los más destacados protagonistas de esta refundación disciplinar de la restauración en España: Solá-Morales i Rubió, González Capitel o González Moreno-Navarro (Lorenzo, 2014, pp. 73-98).
El primero de ellos introducía el vocablo intervención para aquellas nuevas acciones en el Patrimonio a partir de los postulados italianos coetáneos, y exponía que el proyecto contemporáneo debía respetar las esencias del pasado y en los añadidos indagar desde el contraste a la analogía. Por otra parte, defendía la necesidad de dotar de uso a los edificios históricos e intentar conservar las funciones originales, protegiendo al máximo los valores y los esquemas tipológicos por su ser sustancial en la configuración de los edificios (Lorenzo, 2014, pp. 73-98).

González Capitel defendía igualmente los principios de los valores del proyecto, extrayendo de la Historia las leyes para proponer la rehabilitación y el completamiento de los edificios inacabados, en ruinas o que precisaban ser ampliados (González, 2009, pp. 45-62).

En cuanto a González Moreno-Navarro, defendió el método SCCM o restauración objetiva. Sus bases teóricas partían de entender los edificios históricos como documentos históricos y objetos arquitectónicos, dualidad que debía salvaguardarse siempre en la intervención (Lorenzo, 2014, pp. 73-98).

\section{MARCO DE DISCUSIÓN TEÓRICO}

Estas divergencias -y las consecuencias de ciertas actuaciones- propiciaron la celebración de congresos en los que crear un marco de discusión del que pudiesen surgir unas pautas fundamentales para la correcta conservación de un patrimonio que estaba en serio peligro de desaparición: unas veces por causas naturales, otras por destrucciones violentas, por su mal uso y valoración, o por restauraciones radicales estilísticas.

El primer documento al que es preciso referirse es la conclusión emitida por Boito durante el III Congreso de Ingenieros y Arquitectos italianos celebrado en Roma en 1883: el Voto Conclusivo. No se trataba de un escrito oficial; sin embargo, su trascendencia lo identificó como la primera carta del restauro dado el aspecto de compendio de normativa explícita sobre tratamiento de monumentos, exponiendo los principios del restauro científico (Lorenzo, 2014, pp. 51-78).

En relación, se celebró en octubre de 1931 la I Conferencia Internacional de Expertos en la Protección de Monumentos de Arte y Historia. Las conclusiones se recogieron en la Carta de Atenas, escrito en el que por primera vez se formulaban unas normas generales que todo país -estuviese o no representado en ella- debía asumir a la hora de realizar intervenciones en el Patrimonio. Esta conferencia acordaba los criterios de la restauración moderna y destacaba el uso de los monumentos -en la medida de lo posible-para el fin para el que habían sido construidos o en todo caso para un uso digno, que asegurase la continuidad de su vida, respetando siempre su carácter histórico y artístico (Carta de Atenas, art. II).

Un año después se redactó en el seno del Consejo Superior de Antigüedades y Bellas Artes de Roma la Carta del Restauro del 1932, que consagraba y sistematizaba oficialmente las ideas de Giovannoni. Y a pesar de repetir sustancialmente lo expuesto en la carta anterior, establecía como novedad una distinción entre los monumentos arqueológicos -"hoy distanciados de nuestros usos y de nuestra civilización, como son los monumentos antiguos"-; y los llamados monumentos vivos. Esta diferencia se reflejaba en las normas de actuación: mientras en los primeros se permitía solo la anastilosis, en los segundos "se admiten solo aquellos usos no muy alejados de sus destinos primitivos, de tal modo que en las adaptaciones que sean necesarias no se efectúen alteraciones esenciales en el edificio" (Carta Restauro, 1932, art. 3-4).

Los criterios propuestos tanto en esta Carta del Restauro como en las Instrucciones de 1938 -documento que ratificaba los conceptos de la primera, pero que anulaba la diferenciación 
teórica de monumentos en función de sus posibilidades de uso- mostraban una clara tendencia de la evolución de la restauración hacia la necesidad del mantenimiento de los monumentos que conduciría inevitablemente a la conservación preventiva perfilada en los años sesenta en la Carta de Venecia.

Dicha carta -resultado del II Congreso Internacional de Arquitectos y Técnicos de los Monumentos Históricos- ratificaba la consideración de los monumentos como portadores de un mensaje espiritual del pasado y, proponía como criterio fundamental el mantenimiento sistemático de los monumentos y la dedicación de los edificios a usos compatibles con su función originaria con el objeto de no alterar su disposición original.

La conservación de los monumentos se ve siempre favorecida por el uso en funciones útiles a la sociedad: tal finalidad es deseable, pero no debe alterar la distribución y el aspecto del edificio. Las adaptaciones realizadas (...) deben (...) contenerse dentro de estos límites (Carta de Venecia, art. 4-5).

La repercusión de esta Carta en el continente iberoamericano fue significativa: en las recomendaciones de las Normas de Quito de 1967, fruto de una reunión organizada por el Consejo Cultural Interamericano de la Organización de Estados Americanos, se reiteró el beneficio de adherirse a la Carta de Venecia como norma mundial en materia de preservación. Y partiendo de que todo monumento nacional estaba implícitamente destinado a cumplir una función social, adquiría especial relevancia el concepto de puesta en valor para aludir a la rentabilidad de la propiedad del Patrimonio como uso colectivo. "Se trata de incorporar a un potencial económico, un valor actual: de poner en productividad una riqueza inexplotada mediante un proceso de revalorización que lejos de disminuir su significación puramente histórica o artística, la acrecienta" (Normas de Quito, apdo. 6).
De nuevo en Italia, en 1972 se aprobó una segunda Carta del Restauro. Aunque su ámbito era solo nacional, su repercusión fue bastante amplia, suponiendo un enorme avance en cuanta a la metodología europea:

Siempre con el fin de asegurar la supervivencia de los monumentos, se vino considerando la posibilidad de nuevos usos de los edificios monumentales, cuando estos no resulten incompatibles con los intereses histórico-artísticos. Las obras de adaptación deberán limitarse al mínimo, conservando escrupulosamente las formas externas y evitando alteraciones sensibles de la individualidad tipológica del organismo constructivo y de la secuencia de recorridos internos (Carta Restauro 1972, anexo B).

De manera paralela, el Consejo de Europa reactivaba las iniciativas a favor de la protección de un patrimonio común integrado en el marco de vida de la sociedad. Así se celebró el Año Europeo del Patrimonio Arquitectónico en 1975, y como resultado se publicó la Carta Europea del Patrimonio Arquitectónico, cuyos principios se reafirmaron en la Declaración final del congreso celebrado en Ámsterdam. Con ambos documentos se ratificaba la voluntad de promover una política europea común y una acción concertada de protección del patrimonio arquitectónico apoyándose en la adaptación del mismo a las demandas de la sociedad actual.

Lejos de ser un lujo para la colectividad, el uso de este patrimonio es una fuente de economía (...). Ofrece una materia privilegiada de explicaciones (...) del sentido de las formas y multitud de ejemplos de su utilización (...). Interesa, pues, conservar vivos los testimonios de todas las épocas y de todas las experiencias (Carta Europea, ppios. 3-5).
Se tomaba conciencia de la necesidad de utilizar y reutilizar lo existente; aparecía el concepto de rehabilitación como posibilidad de adaptar las estructuras internas de los edificios antiguos dedicados al hábitat y a las necesidades de la vida contemporánea ${ }^{[2]}$. Y a la hora de asignar a los edificios nuevas funciones, estas debían respetar su carácter y responder a las condiciones de vida actual garantizando así la supervivencia del inmueble. "El esfuerzo de conservación debe ser valorado no solo en relación con el valor cultural de los edificios, sino también con su valor de uso" (Declaración Ámsterdam, 3).

En 1981 el Consejo de Europa lanzó la Campaña Europea para el Renacimiento de la Ciudad, donde se recogieron una serie de exigencias - a modo de conclusiones- para fundar ciudades para vivir: se defendía la rehabilitación como un medio esencial para que el patrimonio construido constituyese un recurso fundamental. "Será necesario esforzarse en encontrar nuevos destinos (...) para los edificios antiguos, respetando siempre su carácter" (Conclusiones Berlín, 6).

Con la Convención de Granada en octubre de 1985 se puso punto final a los continuos trabajos realizados durante décadas en el seno del Consejo de Europa. Se trataba de un verdadero convenio que vinculaba a los gobiernos firmantes a adoptar una serie de medidas desarrolladas en torno al concepto de la conservación integrada y que seguía siendo el núcleo de la restauración arquitectónica del momento, no solo en Europa sino también en el continente americano. Quedaba recogido que:

cada parte, si bien respetando el carácter arquitectónico y histórico del patrimonio, se compromete a favorecer el uso de los bienes protegidos, habida cuenta las

[2] El concepto de rehabilitación comenzó a utilizarse -tímidamente- en el Simposio de Avignon de 1968 (Martínez 1996, 37-42). 
necesidades de la vida contemporánea; $y$ la adaptación, cuando resulte apropiada, de los edificios antiguos a nuevos usos (Convención Granada, bloque IV, art. 11).

En septiembre de 1986 se firmó la Carta de Toledo como complemento de la Carta de Venecia, y cuyos principios asumía. Recogía toda la doctrina europea que en materia de la restauración arquitectónica se había ido configurando, especialmente a partir del año 1975. Defendía la conservación de las ciudades y de los barrios históricos, y en cuanto al reúso de edificios especificaba que "las nuevas funciones deben ser compatibles con el carácter, vocación y estructura de la ciudad histórica" (Carta Toledo, art. 8).

El Consejo Nacional de Investigaciones italiano convocaba dos meses después un congreso concluido con la redacción de la Carta del Restauro de 1987. Y a pesar de no haber sido promulgada por ningún organismo ministerial, tuvo una amplia difusión fuera de sus fronteras: quería establecer un estatuto propio que viese las peculiares características de los monumentos y de los contextos ambientales. En lo concerniente a su uso, "se debe destacar qué formas apropiadas de rehabilitación contribuyen a asegurar su supervivencia. (...) Para este fin los trabajos de adaptación deberán limitarse al mínimo respetando (...) la individualidad tipológica y constructiva de la obra, comprendidos sus recorridos interiores" (Carta Restauro 1987, art. 12).

En el año 2000, actuando en el espíritu de la Carta de Venecia y tomando nota de las recomendaciones internacionales, en la Conferencia Internacional sobre Conservación celebrada en Cracovia se fue consciente del contexto de actuación cada vez más amplio en el que las identidades se personalizaban y se hacían más diversas. "Cada comunidad, teniendo en cuenta su memoria colectiva y consciente de su pasado, es responsable de la identificación y de la gestión de su patrimonio". Y la conservación de esta memoria se basaría en la necesidad de educación, que podría realizarse mediante distintos tipos de intervenciones, incluida la rehabilitación.

La finalidad de toda actuación en un edificio histórico o monumento sería el mantenimiento de su autenticidad e integridad de acuerdo con el proyecto original. $Y$ en el caso de un nuevo uso se procuraría respetar en la medida de lo posible la función original, este debería ser compatible con el espacio y el significado existentes. Y "si se necesita, para el adecuado uso del edificio, la incorporación de partes espaciales y funcionales más extensas, debe reflejarse en ellas el lenguaje de la arquitectura actual" (Carta Cracovia, art. 4-6).

\section{CONCLUSIONES}

Debemos conocer y entender nuestro pasado, no solo arquitectónicamente hablando, para afrontar nuestro futuro. Aprendiendo de nuestros predecesores - debates, cartas, pensamientos, corrientes, etc.-, seremos capaces de evitar los problemas derivados de una reutilización o un uso excesivamente intenso o inconveniente de nuestras arquitecturas heredadas.

Dichos problemas se fueron agravando en las últimas décadas hasta el punto de que el reúso monumental llegó a ser una de las principales complicaciones con las que se encontraría el ejercicio arquitectónico europeo. Esto obligó a sopesar con extraordinaria prudencia los pros y los contras y, naturalmente, los programas funcionales propuestos. Incluso un organismo internacional como ICOMOS se vio obligado a proponer como motivo central de sus campañas de trabajo y sensibilización la reivindicación de un uso que permitiese compatibilizar la conservación -en el sentido de continuidad de existir- del inmueble con la permanencia de sus valores esenciales, los que precisamente lo definen como tal.

Recordemos que a finales del pasado siglo se advertía una gran confusión en la que se superponían teorías, tendencias y normativas. $Y$ pese a que eran expuestas distintas posturas, en ocasiones contradictorias, con respeto a la conservación del Patrimonio, se permitió retomar un diálogo anteriormente interrumpido y la restauración integral consiguió desplazar a posiciones teóricas anteriores. Se recomendaba emplear los edificios históricos exclusivamente cuando existiera pertinencia-compatibilidadentre su función original y la función demandada en el presente. Se debía evitar en ellos cualquier distorsión, dado que tanto el precio histórico pagado como el rendimiento conseguido no equilibrarían ni por asomo las ventajas esperadas.

Se intentaba recuperar la conexión perdida tras la intervención entre el nuevo uso y el original, es decir, entre la nueva función y la forma preexistente. Bien es sabido que unas formas, entendidas como tipologías, se adaptan mejor que otras a los nuevos usos, siendo estas adaptaciones más o menos difíciles de afrontar según la compatibilidad del nuevo uso con el original.

No se debe olvidar que las posibles alteraciones semánticas que se produzcan en el monumento durante el cambio de uso pueden devenir en nuevas significaciones en las que las imágenes y símbolos derivados de las diferentes iconografías históricas semejen abocados hacia las orillas confusas del fetichismo.

\section{REFERENCIAS BIBLIOGRÁFICAS}

Carta de Atenas (1931). Recuperado de http://www. icomos.org/en/charters-and-texts/179-articles-enfrancais/ressources/charters-and-standards/167the-athens-charter-for-the-restoration-of-historicmonuments.

Carta de Cracovia (2000). Recuperado de http://www. icomos.org/images/DOCUMENTS/Charters/ cracow_sp.pdf.

Carta de Toledo (1986). Recuperado de http://www. icomos.org/images/DOCUMENTS/Charters/ toledo sp.pdf.

Carta de Venecia (1964). Recuperado de http://www. icomos.org/images/DOCUMENTS/Charters/ venice_sp.pdf. 
Carta del Restauro de 1972. Recuperado de http://www.icomos.org/en/chartersand-texts/180-articles-en-francais/ chartes-et-normes/383-resolutions-of-thesymposium-on-the-introduction-of-contemporaryarchitecture-into-ancient-groups-of-buildings-atthe-3rd-icomos-general-assembly

Carta Europea del Patrimonio Arquitectónico (1975). Recuperado de http://www.icomos.org/en/ charters-and-texts/179-articles-en-francais/ ressources/charters-and-standards/170european-charter-of-the-architectural-heritage

Conclusiones de Berlín (1981). Recuperado de http://www.mecd.gob.es/ipce/dms/mecd/ cultura-mecd/areas-cultura/patrimonio/mc/ ipce/conservacion-y-restauracion/criterios-deintervencion/documentos-internacionales/1981_ Conclusiones_Berlin.pdf

Convención de Granada (1985). Recuperado de http://www.mecd.gob.es/ipce/dms/mecd/ cultura-mecd/areas-cultura/patrimonio/mc/ ipce/conservacion-y-restauracion/criterios-deintervencion/documentos-internacionales/1985_ Convencion_Granada.pdf

Declaración de Ámsterdam (1975). Recuperado de http://www.icomos.org/en/charters-andtexts/179-articles-en-francais/ressources/ charters-and-standards/169-the-declaration-ofamsterdam.
Fontenla San Juan, C. (1997): Restauración e Historia del Arte en Galicia. Santiago de Compostela: Instituto Padre Sarmiento de Estudios Gallegos.

González Capitel, A. (2009): Metamorfosis de monumentos y teorías de la restauración. Madrid: Alianza Editorial.

González-Varas Ibáñez, I. (1996): Restauración monumental en España durante el siglo XIX. León: Colegio Oficial de Arquitectos de León.

González-Varas Ibáñez, I. (2000): Conservación de bienes culturales. Teoría, historia, principios y normas. Madrid: Manuales Arte Cátedra.

Ley del Patrimonio Histórico Español (1933). Recuperado de https://www.boe.es/datos/pdfs/ BOE/1933/145/A01393-01399.pdf

Lorenzo Aspres, A. (2014). Intervencións no patrimonio galego para a industria hostaleira. A Coruña. Recuperado de http://ruc.udc.es/dspace/ handle/2183/13761.

Lorenzo Aspres, A. (2015). A evolución histórica da valoración do patrimonio dende o punto de vista da súa reutilización". Abrente, (46), pp. 385424.

Martínez Justicia, M.J. (1996). Antología de textos sobre restauración. Jaén: Universidad de Jaén.

Miarelli-Mariani, G. (1990). "Historia de los criterios en el patrimonio arquitectónico", En Monumentos y proyecto. Madrid: Ministerio de Cultura, pp. 7-21.
Muñoz Cosme, A. (1989). La conservación del patrimonio arquitectónico español. Madrid: Instituto de Conservación y Restauración de Bienes Culturales.

Normas de Quito (1967). Recuperado de http://www. icomos.org/en/charters-and-texts/179-articles-enfrancais/ressources/charters-and-standards/168the-norms-of-quito.

Ordieres Díez, I. (1995). Historia de la restauración monumental en España (1835-1936). Madrid: Instituto de Conservación y Restauración de Bienes Culturales.

Riegl, A. (2008). El culto moderno a los monumentos. Caracteres y origen. Boadilla del Monte: Antonio Machado Libros.

Rivera Blanco, J.J. (1997). Restauración Arquitectónica desde los orígenes hasta nuestros días. Conceptos, teoría e historia. En Teoría e Historia de la Restauración (pp. 49-81). Madrid: Instituto Español de Arquitectura.

Rivera Blanco, J.J. (2008). De varia restauratione: teoría e historia de la restauración arquitectónica. Madrid: Abada Ediciones.

Rivera Blanco, J.J. (2013). La restauración contemporánea en España: programas, teorías y proyecto 1\% cultural". En Restauración contemporánea: ciudades universitarias, ciudades Patrimonio de la Humanidad (pp. 21-63). Madrid: Universidad de Alcalá de Henares. 